\title{
Gendering Climate Change
}

\section{Af Hilda Rømer Christensen, Michala Hvidt BreengaARd AND HeLENe OldRUP}

Man's impact on the planet is increasing - and so are the costs of our inaction. The world needs a climate agreement that charts a common course for a new beginning, an agreement that adheres to the rationale of the New World Economythe Green Economy.

If we are to succeed bere in Copenbagen - AND WE HAVE TO! then science must inform us and guide our decisions. Or rather: YOU bave to tell US what you know - LOUD AND CLEAR (Danish Climate Minister Connie Hedegaard at the opening of the research conference: Climate Change: Global Risks. University of Copenhagen, March 2009).

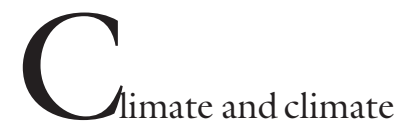

change have been at the forefront of local, regional and global agendas throughout the first decade of the $21^{\text {st }}$ century. Many people, among them scientists, politicians and citizens, are now recognizing that changes to the climate are not only part of a natural development, they have been produced and radicalized by modern ways of production, consumption and mobility. It is now also well recognized that $\mathrm{CO}_{2}$ emissions are unevenly produced, and that the countries of the western world are those mainly responsible for greenhouse gas emissions, but also that the consequences of climate change are affecting the developing world disproportionately. In sum the greenhouse gas emissions produced by modern industry are causing the earth's climate to warm up, with potentially devastating consequences for the future. Global warming has been identified as a problem unlike any other, both because of its scale and because it is mainly about the future. To cope with it, we will need to mobilize 
on a level comparable with fighting a war, except that in this case there are no enemies to identify and confront. "We are dealing with dangers that seem abstract and elusive, however potentially devastating they may be" (Giddens 2009:2).

The aim of this volume of Women, Gender and Research (Kvinder, Kon \& Forskning) is to confront the current climate agenda with gender perspectives and to determine the state of knowledge and research in the field of gender in the politics of climate change in the western world. As such it can be seen as a timely comment on and a critical corrective to mainstream research and political strategies, where the focus on climate mainly emphasises 'genderneutral' technology, economy, energy security and high politics. Many of the articles and essays pay tribute to and qualify the claim that more inclusive approaches, not least the co-reflection of broader social as well as gendered contexts of climate change, will provide better opportunities for achieving the goal of a post-fossil fuel society and a low carbon economy.

We agree with leading climate researchers in their contention that the responses to climate change have been modest in terms of reductions of emissions and efficient measures of adaptation. This is partly because the initiatives have overlooked existing geo-political power relations and inequalities and ignored differentiated potentials for change. This issue on Gendering Climate Change demonstrates that the call for a new beginning should also include gender-sensitive initiatives and gender research.

In her opening article, Death by degrees: taking a Feminist Hard Look at the $2^{\circ} \mathrm{Cli}$ mate Policy, Joni Seager deconstructs one of the strong tropes of international policymakers, who are forging a consensus that a $2^{\circ} \mathrm{C}$ rise in global temperature represents an acceptable and manageable level of danger to the planet. This consensus supports the illusion of big science: that humans can master climate change. However, considerable damage to eco-systems and livelihoods will occur at levels of global warming well below 2 degrees. Seager shows that the 2 degree consensus reflects the point of view of western elites, because devastating effects will happen first and foremost to 'others' and 'elsewhere' than in the West. Feminist analysis, as Seager demonstrates, helps to reveal the gendered political underpinnings of this approach to climate change, where levels of danger and market-based solutions are constructed and accepted.

The overall aspirations of the volume are in line with Seager's account, that is, to make critical interventions and to explore a range of possible avenues towards a gender and diversity politics of climate change focused on the following questions:

- How can the issue of climate change bring about new challenges to key concepts in theoretical gender research and vice versa?

- How can gendered power structures in climate change be critically explored in relation to the distinctions between public and private, human and non-human, local and global governance?

- In what ways can gender analysis be translated into political, scientific and technological innovations and contribute to the enhancement of and change in human knowledge and practices?

\section{FEMINIST GENEALOGIES IN CLIMATE AND ENVIROMENTAL STUDIE}

Eco-feminism has been a vital trend in the feminist genealogy of climate and environmental studies and has played a notable role in women's environmental and climate movements. The eco-feminist paradigm evolved within development studies during the 1980s with the overall aim of opening up a new field and adding a democratic voice to both women and nature. Central to eco-feminist views has been the conviction that gendered systems of power and capital 
accumulation reflect masculine values. This in turn enforces the separation of feminine nature from masculine culture and hence permits the treatment of women and the earth as resources to be controlled and exploited (Sandilands 1999; Alaimo 2008). Eco-feminist thinkers have accordingly urged that masculine traits and practices should be replaced by the promotion of the life-giving principles of women and nature. Some scholars still consider the eco-feminist paradigm as profoundly subversive of present norms and values and as something that can be applied strategically. In the recent book Soil not Oil: Environmental Justice in an Age of Climate Crisis from 2008, the well-known activist and scholar Vandana Shiva radicalizes some of the key notions in relation to transport, agriculture and the recent politics of climate change, of which she is very critical (see review in this volume).

In the wake of poststructuralist and constructionist trends in feminist research, ecofeminism has become contested and has evoked much criticism (Sargisson 2001; Bretherton 2003). In her essay Eco-feminism and its discontents, therefore, Sowmya Dechamma challenges the tendency to essentialize and universalize women's nature and experiences without taking other diversity variables such as class into account. From a different perspective, Kate Soper challenges the tendency to universalise in her essay Beyond Consumerism: Reflections on Gender Politics, Pleasure and Sustainable Consumption. She considers the relationship between women and consumerism, arguing that women's roles in consumerism are diverse. While women have been persuaded to adopt hyper-consumerist habits, they also have taken a lead in anti-consumerist activities. She argues for the need to think beyond consumerism, suggesting that a counter response could be what she calls 'alternative hedonism'.

Several scholars have now endeavoured to relocate this complicated genealogy, as well as trying to carve out a conceptual space from which to avoid the false choices between the eco-feminist romanticising body and nature on the one hand and the poststructuralist and constructivist approaches that tends to do away with the body and nature on the other (Sandilands 1999; Alaimo 2007).

In her article Insurgent Vulnerability and the Carbon Footprint of Gender, Stacy Alaimo applies an approach that she calls 'material transcorporeal feminism' to look at the gendered sciences of global change. She explores the idea of transcorporeality, defined as a site where corporeal theories and environmental theories meet and mingle in productive ways. Transcorporeality places the emphasis on the body and the material interchanges between bodies and global environmental, political and economic systems. This perspective can be seen to be illustrated in this volume by the Danish artist Kirsten Justesen's work (see, for example, the front cover), which embodies a feminist stance toward environmentalism, and by Alaimo's 'insistence on transcorporeality', meaning that we need to recognize the substantial interconnections between human corporeality and the 'more than human' world.

Alaimo's geopolitical base is the U.S., where she criticizes two predominant forms of masculinity: the masculinity of aggressive consumption, which has increased the carbon footprint of the U.S.; and the freefloating, transcendent perspectives presented in official U.S. accounts of climate change. She concludes by providing a critical scrutiny of the current use of the term 'vulnerability', which may reinforce gender dichotomies, heteronormativity and the reduction of the environment to a 'resource'.

Nina Lykke argues in favour of a broader intersectional approach to the analysis of gendered power relations that are entangled in current debates on human and nonhuman natures. In her response to Alaimo, Non-innocent Intersections of Feminism and Environmentalism, she invites us to focus 
on the tensions and conflicting interests not only between the vulnerable and the hegemonic powers, but also among the 'vulnerable themselves'. Lykke concludes with two points which might also stand as a convenient message of this volume. First she warns against the idea of 'purely' radical positions from which purely critical stances and pure alternatives may emerge as illusionary. Secondly and importantly, she ends by asking whether the entire debate on climate change is also undermining positivist epistemology and opening up new avenues for feminist alliances with mainstream research.

\section{THE POLITICS OF GENDER AND CLIMATE CHANGE}

Current climate discourses have been marked by a range of influential rhetorical strategies coloured by powerful political interests and heavily influenced by the neoliberal project of market environmentalism. These narratives have been formalised in international climate conventions, including the 1992 United Nations International Framework Convention on Climate Change (UNFCCC) and the 1997 Kyoto Protocol. Some of the most central mantras are that climate change is to be avoided, that responsibility for climate change is general, but differentiated, and that the Market (in the form of carbon trading) is the best way to reduce climate-related dangers (Seager this volume; Liverman 2009).

Parallel with this, the UN women's commission and a range of women's environmental movements have succeeded in bringing gender issues on to the agenda of current climate debates and policies. The goal has been to gender mainstream the priorities of the UN and other central agents and strategies in accordance with the Platform of Action which, since the UN Women's Worlds Beijing meeting in 1995, has been a guiding principle for global equality activities in the field. ${ }^{1}$
During this process, a range of problems, democratic and knowledge deficits have been identified, such as:

- The need for understanding the differences and inequalities between women and men in relation to natural resource management and livelihood strategies.

- That men and women do not have equal access to extension services, technology, credit and other essential resources.

- That women are not only victims of climate change but may also be powerful agents of change with unique knowledge and expertise, especially at the grassroots level.

- That women are underrepresented in decision-making on sustainable development and climate changes.

- The need for gender mainstreaming of all policies and programmes on sustainable development, and on mitigation and adaptation strategies for technology and capacitybuilding.

- The need for critical work on the gendered consequences and prospects for change at all levels: global, regional, national and local. The need for gender-impact assessments, gender-sensitive indicators and gender-responsive budgeting.

- The need for knowledge production and knowledge-based strategies, and institutional sites at the UN, EU and national levels for the exchange of gendered knowledge and ideas.

All in all there is a need for broad answers to the challenge of climate change, as pointed out by Carolyn Hannan, Director of the DAW (the UN Division for the Advancement of Women) in her essay Gender Mainstreaming Climate Change. Effective responses, she says, require a holistic, multi-sartorial approach which is focused not only on the technical and economic aspects, but also on socio-cultural perspectives.

Yet from the perspectives of women's movements and networks, this very history 
has been one of contestation and resistance, as is shown by Ulrike Röhr, a key activist and expert in local and global movements in her essay $A$ view from the side? Gendering the United Nations Climate Change Negotiations. Here she reveals how, since the 1990s, the gender-based environmental movement has been faced with problems of discontinuity, a lack of resources and clear strategies. It is striking that, along with the professionalisation and bureaucratization of the global environmental movement in such organisations as Greenpeace and Friends of the Earth, women's mobilisation and participation have been marginalized (Röhr in this volume; Bretherton 2003).

Current gender-based environmental movements are faced with critical questions and a need for the clarification of key notions and visions of gender equality, difference and diversity, as well as the role of science and technology. At the same time, the communities are confronted with pressing strategic choices and the dilemmas of institutional framing processes. What are the costs of being included in the mainstream? (Röhr this volume; Bretherton 2003).

Moreover, in our view, many agents need to address the broader aspirations of equality politics that have been introduced at the European and Nordic levels in the all-encompassing idea of 'equality for all' as well as the broader ideas of diversity mainstreaming. This means that identity and structural categories such as gender, class, race, ethnicity, age, sexuality etc., also have to be addressed in the politics of climate change. All in all this invites us to scrutinize the ideas that are around and perhaps even to embark on the critical project of developing more flexible, open and differentiated ideas of gender and nature, as addressed by theoretical gender research.
GENDER MAINSTREAMING CLIMATE CHANGE IN PLANNING, TRANSPORT AND AGRICULTURE

Gender mainstreaming is a global and flexible strategy aimed at gender equality. It can be understood as a continuing process of infusing both the institutional culture and the programmatic and analytical efforts of agencies with gendered perspectives. Gender mainstreaming means taking gender seriously and taking it into account in all aspects of life, culture and society, as well as integrating gender and gendered effects into the products, laws, regulation and services of any institution (Walby 2005; Seager 2005).

One such example is the gender mainstreaming projects of the city of Vienna. Here gender mainstreaming has been applied pro-actively and has been integrated into a range of remarkable initiatives regarding housing, planning, transport etc. as described in Ursula Bauer's essay Gender Mainstreaming in Vienna: How the Gender Perspective Can Raise the Quality of Life in a Big City in this volume.

In her essay Gendering Climate Change Through the Transport Sector, Merritt Polk describes how transport patterns are gendered: overall women have more sustainable transport practices than men. There are still fewer women who are SUV (Sports Utility Vehicle) drivers compared to men, and the recognition of gendered practices in this field might open up new visions for mobility and $\mathrm{CO}_{2}$ reductions (Polk this volume; Transgen 2007).

The relevance of considering the role of men and masculinities in relation to the agenda of climate change and broader environmental strategies is documented by Caroline Crowley in her essay Gendered Identities and Agricultural Sustainability. In the agricultural sector in Ireland, masculine farming identities are strongly committed to conventional, energy-demanding and polluting farming practises. In a more comprehensive view it seems as if new types of 
masculinity may be essential to the future possibility of sustainable agricultural practices.

Ursula Offenberger and Julia Nentwick, in their essay Sustainable Technologies? Home Heating and the Co-construction of Gender, Technology, and Sustainability, explore how technologies (here the field of sustainable heating technologies) are intertwined with symbolic gender orders. Their aim is to draw attention to how gender, technology and sustainability are intersecting phenomena and therefore can not be treated as separate issues. This is a promising perspective, which is highly relevant for future low-carbon societies.

\section{VOICES FROM COPENHAGEN 2009}

In Denmark the topics of climate and sustainability have, of course, been given great attention in recent years because of Copenhagen's role as host of the COP 15 in December 2009. According to the Danish Climate Minister, Connie Hedegaard, a loud and clear response from science is needed in order to provide the right future conditions for change, as well as an appropriate basis for the launch of a new global climate change agreement.

While the UN and other global institutions are now trying hard to address and gender mainstream climate debates, the European Union and major women's organisations, such as the European Women's Lobby, have been remarkably silent in the process of gender mainstreaming climate change. This volume is also an invitation to the European Union and other European and national agents to take up this challenge. We urge all parties to make critical interventions in politics and research in the areas of climate change in line with the strong European commitment to the principle of gender mainstreaming in social and political areas

We find it highly relevant to include gender and equality in answers, reflections and perspectives on climate change. This is because gender and gender equality count among the core values of Danish society, but also because gender research has the potential to add new and substantial perspectives to current debates and strategies on climate and sustainability.

By now there is a pressing need for more knowledge and research in this area, as well as a need to deconstruct the strikingly western masculine, scientific bias in the dominant climate discourses, and to identify possible scientific alliances in the search for new conceptual and theoretical avenues.

All in all, this issue of the journal bears witness to the plurality of approaches and key notions that exist in feminist research and practices today. While some have entered the realm of materialist or post-constructivist gender research, leaving the former eras of eco-feminism and constructionist gender research behind, others remain elsewhere in a hybrid situation, where old and new agendas are being played out in radicalised, revised and displaced forms. It has been an aim of the perspectives and insights of $21^{\text {st }}$ century scholarly and political expertise to make visible the role and implications of gender in the making of a politics of climate change, as well as, hopefully, to forge links, conversations and translations across institutions, disciplines and all other borders.

Many of the contributions in this volume are edited papers deriving from the conference on Gendering Climate and Sustainability convened by the University of Copenhagen in March 2009. The conference was arranged by the Co-ordination for Gender Studies and supported by an advisory board of researchers within and outside the university. We would like to thank the University of Copenhagen for financing the conference and this volume in the context of the current university priority area on Sustainability, Globalization, Environment and Development, together with the Danish Research Council (FSE). 


\section{Notes}

1. Beijing Declaration and Platform for Action adopted by the Fourth World Conference on Women: Action for Equality, Development and Peace, Beijing, 15 September 1995, where the principle of gender mainstreaming was launched along the inclusion of Environment as one of the focal points.

\section{LITERATURE}

- Alaimo, Stacy (2008): Trans-corporeal Feminism and the Ethical Space of Nature, in: Alaimo, Stacy and Hekman, Susan (eds.): Material Feminisms. Indiana University Press. Bloomington and Indianapolis.

- Bretherton, Charlotte (2003): Movements, Networks, Hierarchies. A Gender Perspective on Global Environmental Governance, in: Global Environmental Politics 3.2. 2003, 103-119.

- Giddens, Anthony (2009): The politics of Climate Change. Polity Press, Cambridge.

- Liverman, Diana M. (2009): Conventions of Climate Change. Constructions of Danger and the Dispossession of the Atmosphere, in: Journal of Historical Geography. Vol, 5, issue 2, April 2009. Walby, Sylvia: Gender Mainstreaming: Productive Tensions in Theory and Practice, in: Social Politics: International Studies in Gender, State \& Society. November 8, 2005. http://sp.oxfordjournals.org/cgi/content/full/1 $2 / 3 / 321$ ? ijkey=yFk0XdpzrxyGm8C\&keytype $=$ ref Sandilands, Catrioni (1999): The Good Natured Feminist: Ecofeminism and the Quest for Democra$c y$. University of Minnesota Press.

- Sargisson, Lucy (2001): What's wrong with Ecofemnism, in: Environmental Politics 10 (1), 52-64. - Seager, Joni and Betsy Hartman (2005): Mainstreaming Gender in Environmental Assessment and Early Warming. UNEP (United Nations Environment Programme). Report 1-82.
- Shiebinger, Londa (ed.) (2008): Gendered Innovations in Science and Technology. Stanford University Press.

- Transgen (2007) Gender Mainstreaming European Transport Research and Policy. Building the Knowledge Base and Mapping Good Practices. The Co-ordination for Gender Research (2007) University of Copenhagen. Download at http://koensforskning.soc.ku.dk/projekter/transgen/

Hilda Rømer Christensen, PhD, Associate Research Professor

Head of the Co-Ordination for Gender Studies in Denmark. Department of Sociology, University of Copenhagen

Editor in chief of Kvinder, Kon \& Forskning

(Women, Gender \& Research)

Organiser of the international research conference Gendering Climate and Sustainability, University of Copenhagen, March 2009

Michala Hvidt Breengaard, cand.scient.soc., Research Assistant

The Co-Ordination for Gender Studies in Denmark. Department of Sociology, University of Copenhagen

Sub-editor of Kvinder, Køn \& Forskning (Women, Gender \& Research)

Organiser of the international research conference Gendering Climate and Sustainability, University of Copenhagen, March 2009

Helene Hjorth Oldrup, cand.techn.soc, PhD, Researcher

SFI - Det nationale forskningscenter for velfærd (The National Research Center for Welfare) Organiser of the international research conference Gendering Climate and Sustainability, University of Copenhagen, March 2009 